\title{
Risco e insegurança no Correio do Povo e Zero Hora: a construçãode sentidos relacionados às drogas ilícitas
}

\author{
Riskandinsecurity in Correio do Povo e Zero Hora: \\ the construction of meaning related to illicit drugs \\ Riesgo y inseguridaden Correio do Povo e Zero Hora:laconstrucción de los \\ sentidos relacionados a las drogas ilegales \\ Anelise Schütz Dias ${ }^{1}$ \\ Isabel Padilha Guimarães ${ }^{2}$ \\ http://dx.doi.org/10.5216/32084
}

\begin{abstract}
Resumo
O presente trabalho tem como objetivo identificar os sentidos de risco e insegurança contidos no discurso dos jornais impressos Zero Hora e Correio do Povo nos textos que fazem referência ao consumo e à circulação de drogas ilícitas no Rio Grande do Sul. O aporte-teórico metodológico utilizado neste artigo é o da Análise do Discurso de linha francesa e como categorias de observação foram aplicados os conceitos de risco, discursos da violência e individualização das vítimas, extraídos da obrados teóricos Paulo Vaz, Roberto Damatta e Robert Reiner. Ao todo, foram selecionadas 19 matérias de ambos os jornais, a partir do marcador "drogas". Na maioria delas, os discursos se estruturam em torno da segurança pública, da criminalidade e do desvio social. Além disso, as fontes institucionais, vinculadas aos órgãos de repressão, apareceram em recorrência e colaboraram na construção de sentidos como risco e insegurança, além de contribuírem para o reforço estereótipos criminais.
\end{abstract}

Palavras-chave: Drogas. Risco. Discursos da violência. Individualização das vítimas.

\begin{abstract}
This paper has as objective identify the senses of risk and insecurity contained in the speeches of the newspapers Zero Hora e Correio do Povo in the texts that refers to the use and circulation of illicit drugs in Rio Grande do Sul. The methodological-theoretical approach this article is the French Discourse Analysis and as observation categories were applied the concepts of risk, violence speeches, and individualization of victims, extracted from the theorical work of Paulo Vaz, Roberto Damatta e Robert Reiner. In total, were selected 19 material of both newspapers, from "drugs" marker. In most of all, thespeeches are structured around public safety, criminality and social deviance. Furthermore, the institucional sources, liked to enforcement agencies, appeared with recurrence and contributed to the construction of sense as risks and insecurity and contribute to the strengthening of criminal stereotypes.
\end{abstract}

Key-words: Drugs.Risk. Violence speeches. Individualizationofvictims.

\section{Resumen}

Este estudiotiene como objetivo identificar los sentidos de riesgo e inseguridad que figuranenel discurso de los periódicos Zero Hora y Correio do Povo en textos que se refieren a lautilización y

\footnotetext{
${ }^{1}$ Mestranda na linha de Mediações e Representações Culturais e Políticas do Programa de Pós Graduação em Comunicação e Informação (PPGCOM) da Universidade Federal do Rio Grande do Sul (UFRGS), Brasil, Rio Grande do Sul, Santa Maria. E-mail: anelisesdias@gmail.com

${ }^{2}$ Doutor em Comunicação Social pela Pontifícia Universidade Católica do Rio Grande do Sul (PUCRS). Professora na Universidade Federal de Santa Maria (UFSM), Brasil, Rio Grande do Sul, Santa Maria. E-mail: isabel.padilha@yahoo.com.br
}

Comun. \& Inf., Goiânia, GO, v. 18, n. 1, p. 07-20, jan./jun. 2015 
elcirculación de drogas ilícitas en Rio Grande do Sul. El enfoque teórico-metodológico deste artículo es elanálisisdel discurso francés y como categorías de observación se aplicaronlos conceptos de riesgo;discursos de laviolencia; y individualización de lasvíctimas, tomados de las obras de los teóricos Paulo Vaz, Roberto Damatta y Robert Reiner. En total, se seleccionaron 19 textos de ambos periódicos, desde lo marcador "drogas". Enlamayoría de ellos, los discursos se estructuranen torno a laseguridad pública, elcrimen y ladesviación social. Además, lasfuentesinstitucionales, vinculados a lasfuerzasrepresivas, aparecieronenrecurrencia y colaboraronenlaconstrucción de significado riesgo y inseguridad y contribuyentambién a reforzarlosestereotiposcriminales.

Palabras-clave: Drogas. Riesgo. Discursos de laviolencia. Individualización de lasvíctimas.

\section{INTRODUÇÃO}

1 relação entre a circulação de drogas ilícitas na sociedade e a segurança pública é 1 pauta cotidiana nos jornais gaúchos. A discussão, em geral, se polariza na 1 necessidade de conter o tráfico através do recrudescimento da legislação e da execução das penas já existentes. O tratamento do tema, a partir da perspectiva da saúde pública e dos direitos humanos, pouco encontra espaço para divulgação dentre as páginas dos jornais. Ações sociais, políticas públicas do Estado e projetos que se preocupam em atuar na promoção dos direitos básicos de cidadania a grupos sociais mais sujeitos à violência não chegam, muitas vezes, a ser de conhecimento público ou, quando chegam, são pelo viés da crítica, como mostra o corpus deste trabalho.

A cobertura jornalística aqui observadafoi construída, na maioria dos casos, a partir de informações de fontes institucionais das polícias e de outras forças coercitivas institucionalizadas, as quais apareceram, muitas vezes, como únicas fontes de consulta e transferem para o discurso jornalístico a forma como o Estado ainda percebe e combate o tráfico, que é a lógica do inimigo.

Na relação entre o "eu" e o "outro" mediada por esse jornalismo, este representa o perigo e deve ser expurgado do corpo social. E é preciso que o "eu" monitore as ações do "outro" e as represálias por ele sofridas. Dessa forma, somos levados a acreditar pelo noticiário que,a todo o momento, podemos ser mais uma das vítimas da criminalidade, pois, supostamente, vivemos em uma crise de segurança individual devido ao risco potencial de sermos por ela vitimados. Neste sentido, o jornalismo contribui, ao fomentar ideias de risco e insegurança, para que acreditemos ser necessário colocar de lado algumas garantias individuais, como a liberdade de ir e vir, em nome da segurança.

O objetivo central deste trabalho ${ }^{3}$ éidentificar os sentidos de risco e insegurança contidos no discurso dos jornais impressos Zero Hora e Correio do Povo ${ }^{4}$ nos textos que fazem

${ }^{3}$ Este artigo é um recorte da monografia "Jornalismo, risco e insegurança: uma análise dos discursos sobre drogas ilícitas nos jornais Zero Hora e Correio do Povo", defendida no Curso de Jornalismo da Universidade

Comun. \& Inf., Goiânia, GO, v. 18, n. 1, p. 07-20, jan./jun. 2015 
referência ao consumo e à circulação de drogas ilícitas no Rio Grande do Sul. Como categorias de análise foram escolhidos três conceitos extraídos da obra dos autores-base da discussão proposta, que são risco(VAZ, 2004), discursos da violência (DAMATTA, 1993) e individualização das vítimas(REINER, 2002). A escolha de tais categorias foi um caminho metodológico encontrado após uma observação primeira do corpus que evidenciou que essas são as que melhor reúnem, dentre as possibilidades proporcionadas pelo referencial teórico, os sentidos que buscamos identificar como objetivo deste trabalho.

Ao todo, foram 19 matérias analisadas,selecionadas a partir do marcador textual "drogas" e, organizadas, em uma etapa inicial, de modo que ficasse evidente o título, o veículo em que foram publicadas, a data de publicação, a editoria, o formato textual e as fontes consultadas. Essas matérias tratavam, principalmente, de ações de repressão ao tráfico em Porto Alegre e seus arredores.

No período analisado, a cobertura da temática "tráfico e circulação de drogas" se mostrou quantitativamente superior no jornal Zero Hora: 11 dos 19 textos coletados foram publicados nesse jornal. Os outros oito foram encontrados no Correio do Povo.A opção pelos veículos diários foi uma escolha que permitiu que observássemos a presença constante da temática do consumo e da circulação de drogas no discurso jornalístico em casos comuns ao cotidiano.Como aporte teórico-metodológico, optamos pela a Análise do Discurso Francesa, a partir da perspectiva pecheuxtiana de EniOrlandi (2009). Os autores-base Robert Reiner (2002), Roberto Damatta (1993) e Paulo Vaz (2004).

\section{RISCO, VIOLÊNCIA E CONSTRUÇÃO DE ESTEREÓTIPOS}

A presente análise faz uso de uma perspectiva discursiva para compreenderos sentidos de risco e insegurança nos enunciados jornalísticos que abordam as questões sobre a circulação de drogas na sociedade e sua relação com a segurança pública. Partimos da perspectiva pecheuxtiana de Orlandi $(2009$, p.9) de que "a Análise de Discurso, como seu próprio nome indica, não trata da língua, não trata da gramática, embora todas essas coisas lhe interessem. Ela trata do discurso. E a palavra discurso, etimologicamente, guarda em si a ideia

Federal de Santa Maria em dezembro de 2013, sob a orientação da Pós-Doutoranda Isabel Padilha Guimarães e coorientação da Professora Pós-Doutora em Comunicação Ada Cristina Machado da Silveira.

${ }^{4} \mathrm{~A}$ escolha dos jornais impressos Zero Hora (ZH) e Correio do Povo foi motivada pelo fato de ambos pertencerem a grupos de comunicação com bastante expressão no Rio Grande do Sul e serem os veículos de maior circulação nas cidades gaúchas. Em 2012, a ZH ocupava a 6 a posição no ranking dos maiores jornais em circulação paga do Brasil da Associação Nacional dos Jornais, totalizando cerca de 185 mil exemplares por dia. Já o Correio do Povo era o $9^{\circ}$ jornal de maior circulação paga no país, com a distribuição de 150 mil exemplaresdia.

Comun. \& Inf., Goiânia, GO, v. 18, n. 1, p. 07-20, jan./jun. 2015 
de curso, de percurso, de correr por, de movimento". Essa perspectiva percebe o discurso como prática de linguagem, como prática discursiva que também é uma forma de ação social, determinada pelos contextos históricos, políticos, sociais, geográficos, etc.

Sobre os meios de comunicação, Rodrigo (2009) defende que esses estabelecem um horizonte cognitivo e emotivo para seus destinatários, contribuindo para a demarcação das fronteiras entre o "eu" e o "outro(s)" e para a concretização dos processos de construção identitária. Para dar sentido ao mundo à sua volta, o ser humano realiza uma operação complexa, na qual utiliza-se de um universo referencial simbólico adquirido através das práticas sociais. Neste universo simbólico estão contidas as representações sociais, que são formas de conhecimento socialmente elaboradas e partilhadas, que contribuem para nomearmos e interpretarmos situações da vida cotidiana (JOVCHELOVITCH, 2000). O autor entende o repertório simbólico individual como um campo de contradições, no qual está presente a polifasia $\operatorname{cognitiva}^{5}, \mathrm{e}$, por isso, qualquer tentativa de conceituá-lo de uma forma única seria reducionista:

Estamos diante de um conteúdo heteróclito e homogêneo, paradoxal e coerente, fixo e mutante, que é composto de sentido comum e de conhecimentos científicos, de razão e de paixão, de valores e de dados, de logos e mythos, de julgamentos e preconceitos, de estereótipos e de longas reticências. (ALSINA, 2009,p.274).

Dessa forma, as representações sociais aparecem como instrumentos que nos ajudam a dar sentido às realidades que nos circundam, ainda que, muitas vezes, por meio do acionamento de preconceitos e estereótipos que nos ajudam a reduzir a complexidade da realidade social. Para Rodrigo (2009, p.274), “os preconceitos e estereótipos tranquilizam a nossa ansiedade e a nossa incerteza diante da falta de sentido de uma situação". O que pode contribuir para que o "eu" enquadre o "outro" em esquemas categóricos previamente estabelecidos, classificando-os sem observá-lo em profundidade.

As representações sociais, seus estereótipos e pré-conceitos, estão presentes também no discurso jornalístico, o qual é produto e produtor da realidade social em que estão em circulação essas representações. Desse modo, quando o jornalismo se vale desses esquemas categóricos mais rasos para representar e mediar situações do cotidiano, perde-se em profundidade e em contextualização. O que corre também quando as fontes jornalísticas ficam restritas a um grupo de pessoas com influência em determinas áreas, legitimando-se como

\footnotetext{
${ }^{5}$ Polifasia cognitiva é um conceito de Moscovici (1976), muito utilizado por autores da psicologia social. De acordo com Jovchelovitch (2004), "apolifasia cognitiva refere-se a um estado em que registros lógicos diferenciados inseridos em modalidades diferentes de saber coexistem em um mesmo indivíduo, grupo social ou comunidade".
}

Comun. \& Inf., Goiânia, GO, v. 18, n. 1, p. 07-20, jan./jun. 2015 
definidores de determinadas temáticas, que oferecem enquadramentos que refletem apenas percepções institucionais ou pessoais.

Em sua análise do noticiário britânico sobre o crime, violência e criminalidade, Reiner (2002) percebeu que a Polícia e a Justiça criminal apareciam como detentoras das informações de que necessitavam os repórteres que participavam dessa cobertura. Tal situação instituía uma relação de poder em que estas instituições apareciam como fontes legitimadas como interpretantes primários dos fatos, o que não somente dava a elas lugar de destaque, como eram elas que definiam os termos de referência em que se desenvolvia o debate acerta do evento relatado. ParaWelch eFenwick (1998, p.70), "operando no estágio final da construção social do crime, os líderes políticos e os executores oficiais das leis(também conhecidos como gestores do Estado) desfrutam do privilégio de oferecer à mídia as principais, bem como ideologicamente posicionadas, definições sobre o crime."Esses autores entendem a atuação dos gestores do Estado como as de gatekeepers ${ }^{6}$, que filtram as definições e os enquadramentos das histórias sobre crime que serão apresentadas pelo jornalismo para a sociedade:

Gestores do Estado e a mídia, juntos, determinam o que é socialmente pensável (e.x. violência cometida unicamente por predadores individuais ao invés de corporações infratoras). Beneficiando-se da sua elevada posição dentro de uma hierarquia de credibilidade (Becker 1973, 1967), gestores de Estado também promovem e legitima sua agenda de "lei-e-ordem" de controle do crime (ERICSON, BARANEK, andCHAN 1991, 1989, 1987; FISHMAN 1978; HALL et al. 1978; SURETTE 1992; HUMPHRIES 1981 apud WELCH, FENWICK, ROBERT, 1998, p.70-71).

No Brasil, assim como na Inglaterra, a cobertura jornalística da segurança pública apresenta forte dependência das informações fornecidas pela polícia,segundo Ramos e Paiva (2007), que fizeram um levantamento em mais de dois mil textos publicados em diferentes jornais de três estados brasileiros:

Em 2004, uma análise de 2.514 textos publicados em nove jornais de três estados demonstrou que a polícia era a principal fonte ouvida em $32,5 \%$ dos casos. Quando eram desconsiderados os textos que não indicavam fontes notas e colunões, rápidos registros de encontros de cadáveres, roubos e outras ocorrências, que compunham $24,8 \%$ da amostra - o percentual subia para 43,2\%. Em outro levantamento, realizado pelo CESeC em 2006 sobre oito jornais do Rio, 5 26,9\% dos 2.651 textos baseavam-se em informações policiais. Além destes, um grande número dos colunões e notas, que

\footnotetext{
${ }^{6}$ Para Alsina (2009, p.214) "gatekeeper tem sido traduzido de muitas formas: porteiro, guarda-cancela, guarda barreira". Propõe ainda a tradução de "selecionador", uma vez que considera "que se ajusta muito mais à função comunicativa que ilustra".
} 
compunham 34,6\% da amostra, tinha como fontes os boletins de ocorrência. (RAMOS, PAIVA, 2007, p. 37).

Porém, não é o fato de as fontes já naturalizadas - as provenientes das Polícias Civil, Militar e Federal, principalmente - serem recorrentemente utilizadas que alarma as autoras, mas sim ter sido constatado que mais de $50 \%$ das reportagens analisadas na pesquisa apresentam a versão de apenas uma pessoa ou instituição. Tal situação, que restringe os atores sociais autorizados ao debate e também a possibilidade de construção de contrapontos, é percebida em 15 das 19 notícias analisadas no corpusdessa pesquisa, as quais possuem apenas uma fonte, citada ou não, que é proveniente das forças policiais.

Para Ramos e Paiva (2007, p.37), ainda, "a consequência mais grave da dependência das informações policiais é que ela diminui a capacidade da imprensa de criticar as ações das forças de segurança", já que a cobertura se baseia, majoritariamente, no registro de prisões, de apreensões e de investigações criminais. A pesquisa realizada pelo Centro de Estudos de Segurança e Cidadania e referenciada no livro Mídia e Violência, organizado por Silvia Ramos e Anabela Paiva, aponta ainda que as vítimas aparecem em segundo lugar como fontes consultadas - correspondendo a 9,7\% no levantamento nacional. Em terceiro lugar, estão os poderes executivos, em suas esferas federal, estadual e municipal, em torno de $8,5 \%$. Apenas $4,6 \%$ das fontes são especialistas em segurança pública. E, à sociedade civil organizada, é dedicado menos de $1 \%$ do espaço na imprensa nacional. Os dados, segundo as autoras, apontam para uma cobertura de pouca diversidade, em que predomina a descontextualização e a ausência da pluralidade de vozes. Nela, temas como direitos humanos, violência enquanto fenômeno social, raça e etnia, gênero e violência doméstica, por exemplo, são pouco frequentes." (RAMOS E PAIVA, 2007, p. 39).

$\mathrm{Na}$ abordagem jornalística analisada neste artigo, os papéis sociais se mostram definidos e construídos pelas fontes, que aparecem, majoritariamente, centradas nas figuras das polícias e das forças jurídicas do Estado. O enquadramento dado às notícias vai depender do que é entendido por 'crime' e a penalidade atribuída a ele em cada contexto. Diferentes sociedades possuem diferentes percepções sobre os conceitos violência, crime e criminalidade. Richard Ericson (1987, p.3 apud REINER, 2002, p.380) propõe que a definição de crime que é utilizada pela mídia noticiosa britânica é a de "desvio social”, o que ele explica como"o comportamento de uma coisa ou pessoa que desvia da normalidade, não somente atos criminais, mas também, desvios dos processos organizacionais e violações do conhecimento senso-comum”. (ERICSON, 1987, p.4 apudREINER, 2002, p.380). 
Para Silva (2007), no Brasil, a cobertura jornalística fomenta o pânico das elites serem vítimas da violência, ainda que esse medo esteja em desacordo com as estatísticas oficiais. Musumeci (2007, p.154) atenta para o fato de que os jornais tendem a centralizar as práticas criminosas relatadas nas áreas em que moram seu público-alvo. Para a autora, a ausência de estatística oficiais nas reportagens e nas notícias pode induzir o leitor a uma distorção na forma com que percebe e a reage ao problema, "como a impressão de que áreas 'nobres' são as mais afetadas pela violência, já que os crimes mais violentos que nelas ocorrem aparecem assiduamente na mídia".A autora aponta, ainda, para a diferenciação dos entendimentos de crime e violência - dois conceitos utilizados, recorrentemente, como consequentes diretos na mídia noticiosa:

Como se vê, crime e violência são conceitos de naturezas distintas. O primeiro parte do ordenamento jurídico existente numa dada época em certa sociedade - que explicita os atos puníveis, sejam eles violentos ou não, classifica-os segundo a modalidade e a gravidade, e determina as penas aplicáveis a cada caso. Já o conceito de violência designa um aspecto das ações humanas, sejam elas puníveis ou não, que é a capacidade de causar danos físicos ao próprio agente e/ou a terceiras pessoas.(MUSUMECI, 2007, p.154).

O cenário político brasileiro é marcado por fortes ligações com as posturas normativas, como observa Roberto Damatta (1993, p.175-176). Tal situação pode ser confirmada na forma com que é realizada a análise da violência e do crime: "quando falamos destes temas, sempre produzimos um discurso organicista e formalizante, [...] rejeitando qualquer atitude que primeiramente questione a natureza do fenômeno em suas linhas mais gerais".Damatta propõe que há duas formas discursivas da violência: a leitura teórica ou erudita e a do senso comum. $\mathrm{O}$ discurso erudito apresenta um "acentuado viés normativo, juridicista, formalista e/ou disciplinador" (ibidem, p.179), que tende a diagnosticar, ao invés de compreender as condições que levam à violência sistêmica, e oferecer sugestões através de medidas normativas. Esses discursos, segundo o autor, normalmente se encerram em pedidos de novas medidas legais para enfrentar o problema.

O discurso do senso comum, outra forma de retórica da violência referenciada por ele, se baseia na experiência diária, nas relações interpessoais. Nele, a violência perde seu caráter de fenômeno histórico e aparece como um mecanismo social indesejável: "uma ação espontânea, reparadora e direta que rompe os espaços e as barreiras dos costumes, as normas legais, e invade de qualquer maneira o espaço moral do adversário.” (DAMATTA, 1993,

Comun. \& Inf., Goiânia, GO, v. 18, n. 1, p. 07-20, jan./jun. 2015 
p.180). O autor acredita que esses dois tipos de discursos se fazem presentes na sociedade brasileira e que são complementares e até mesmo simétricos, uma vez que o discurso do erudito não é capaz de expressar o que o do senso comum tende a acentuar e vice-versa:

Assim, o discurso erudito é incisivo em relação à estrutura do sistema, mas nada diz que permite dar um sentido sociológico profundo à violência do dia-a-dia. Afinal, como é que essa fala econômica e política sofisticada e sistêmica pode explicar a violência que atingiu o meu grupo, a minha família ou os meus entes queridos? (DAMATTA, 1993, p.184).

O senso comum é o discurso que remete ao universo da casa, das intimidades. A partir desse ponto de vista, "explicar um crime por meio de uma estatística é um insulto, pois ele demanda a confrontação do caso em sua especificidade e sua pessoalidade, elementos que a sociedade brasileira vê como componentes importantes da realidade e da vida" (DAMATTA, 1993, p.185).

Assim como no restante da sociedade brasileira, no jornalismo, ambas as formas discursivas aparecem como complementares, mas nem sempre são simétricas. $\mathrm{O}$ discurso jornalístico parece pender, na maioria das vezes, para o senso comum que pessoaliza e individualiza as vítimas, descontextualizando as ações criminosas e as enquadrando comumente pelo viés do agente policial que atendeu a ocorrência ou investigou o caso. É também recorrente a presença de parentes das vítimas como fontes, reforçando o caráter individualizante de cada caso por meio do resgate de pontos da trajetória pessoal do atingido pela violência.

Se o senso comum traz a compreensão da violência para o universo das relações da casa, os jornais tendem, como o observado por Musumeci (2007), a territorializar a cobertura sobre a criminalidade nas ações criminosas cometidas nas áreas em que vivem/circulam seu público-alvo. Tal situação gera, como o exposto por Reiner (2002), um exagero na percepção de risco a que alguns estratos sociais estão expostos.

Em um trecho-exemplo, selecionado de uma das reportagens contidas no corpus dessa pesquisa, é possível perceber o fomento da ideia do risco a que os indivíduos estão sujeitos ao circularem pela capital gaúcha enquanto 500 apenados do regime semiaberto estão nas ruas sem o monitoramento eletrônico devido a uma falha nos aparelhos de vigilância:

Ex.: Equipamentos apresentaram defeitos em um parafuso e, enquanto não são substituídos, os detentos seguem à solta. $\mathrm{O}$ descontrole sobre parte do grupo já chega há 30 dias. Durante esse período, apenados circulam por qualquer lugar sem serem importunados. Como estão legalmente nas ruas, só 
poderão ser presos caso se envolvam em novos crimes. (Zero Hora, 27/08/2013).

Outras sequências discursivas que apontam riscos da violência e da criminalidade a que está sujeito o público leitor foram igualmente observadas nas notícias pesquisadas. A recorrência dos alertas percebidos no discurso jornalístico, principalmente no jornal Zero Hora, vai ao encontro da consideração de Vaz (2004) de que a preocupação com os riscos de ser vitimado pelo crime e pela violência é fator central na vida da classe média brasileira. Por risco o autor entende uma ação futura não desejada que possa causar sofrimento. No jornalismo, o conceito de risco implica trazer para o discurso do presente a possibilidade de acontecimentos futuros indesejados e formas de evitá-los. Para o autor, a adesão às políticas de ordem e de lei dependerá, ainda, do grau de credibilidade que os aparelhos de segurança e punição têm frente à população.

No Brasil, Vaz (2004, p.20) considera que há expressivo descrédito e ceticismo em relação a esses aparatos, o que parece ser retroalimentado cotidianamente pela mídia noticiosa, a qual seguidamente aponta que, para crimes como tráfico de drogas, por exemplo, as normas jurídicas e a ação coercitiva do Estado são insuficientes para conter os riscos a que os cidadãos estão expostos: "a apropriação do conceito de risco pela classe média, porém, faz com que a causa pública no discurso contra o crime não tenha mais nenhuma possibilidade universal no futuro; a segurança de uns depende da contenção do risco posto por outros".

Ao escolher as forças coercitivas do Estado como fontes legítimas, o jornalismo contribui para o reforço de estereótipos criminais, ideias de delinquência, além de se constituir em um especialista em normalidade, que julga os desvios e dita padrões de comportamento.

Outro exemplo encontrado nas notícias analisadas corrobora a noção de ação normativa do jornalismo utilizada para reivindicar aumento no suporte político e soluções mais duras para reestabelecer a lei e a ordem. Em 22 de setembro de 2013, o jornal Zero Hora publicou um editorial intitulado "O tamanho da tragédia", que trata sobre o crescimento exponencial do consumo de crack no Brasil.

Ex.: Aí está o xis da questão: mesmo com programas bem-intencionados, tanto oficiais quanto por parte de ONGs, o Brasil parece estar perdendo a batalha para essa droga que vicia nas primeiras experimentações e degrada a vida dos consumidores. Sinal de que as políticas públicas precisam ser redirecionadas para as ações inovadoras e talvez mais radicais. (Zero Hora, 22/09/2013). [grifos nossos] 
O trecho evidencia um discurso sobre a falência das iniciativas do Estado e a necessidade de enrijecimento das ações políticas. Nesse editorial, há um exacerbado apontamento dos danos causados no corpo social pelo consumo de crack, porém não há uma análise comparativa sobre os impactos da circulação entre essa e outras drogas no país, por exemplo.

\section{RISCO, DISCURSOS DA VIOLÊNCIA E INDIVIDUALIZAÇÃO DAS VÍTIMAS COMO CATEGORIAS DE SENTIDO}

Como já dito anteriormente, o procedimento central desta pesquisa atém-se à análise discursiva do corpus selecionado. O objetivo geral é identificar os sentidos de risco e insegurança contidos no discurso dos jornais impressos Zero Hora e Correio do Povo por meio de uma análise comparativa entre ambos. Como forma de sistematizar a análise foram utilizadas três categorias discursivas, baseadas em conceitos expostos pelos autores que compõem o referencial teórico deste trabalho. São elas: risco(VAZ, 2004), discursos da violência - erudito e senso comum (DAMATTA, 1993), individualização das vítimas(REINER, 2002). A escolha pela construção de uma semana artificial, a partir de edições recolhidas aleatoriamente ao longo dos meses de agosto e setembro de 2013, foi a alternativa encontrada para evitar que os textos observados se confinassem a uma cobertura específica de algum caso que houvesse repercutido em um curto período corrente. As publicações selecionadas para esta análise correspondem, portanto, aos dias 02/09/2013 (segunda-feira), 27/08/2013 (terça-feira), 18/09/2013 (quarta-feira), 26/09/2013 (quinta-feira), 11/10/2013 (sexta-feira), 05/10/2013 (sábado) e 22/09/2013 (domingo), dos referidos veículos.

A indicação do sentido discursivo de risco de a sociedade ser vitimada pela violência decorrente do tráfico foi constatada em quatro textos jornalísticos do jornal Zero Hora, são elas: "Recall de tornozeleiras: 500 presos na rua sem vigilância" (reportagem - 27/08/2013); "O tamanho da tragédia" (editorial - 22/09/2013); "Guerra urbana: na hora e no local errados" (reportagem especial - 22/09/2013); "Nem a escola escapa da guerra das quadrilhas" (nota 11/10/2013). Embora os textos tenham formatos diferentes, a construção discursiva na construção do sentido de risco é bastante semelhante, o que pode ser percebido já nos títulos das matérias. Também pode ser observado no trechos-exemplo extraído do editorial supracitado: 
Ex.: significa a existência no país de um verdadeiro exército de dependentes, com todas as implicações que esta condição impõe para a saúde desses indivíduos, para a desagregação de suas famílias e até mesmo para a segurança da sociedade. (Zero Hora, 22/09/2013)[grifos nossos]

Ex.: Não é incomum que dilemas relacionados ao consumo de crack terminem em tragédias familiares. $\mathrm{E}$ quem tem a sorte de não ter $\mathrm{o}$ problema em casa também não está livre de suas consequências, pois os usuários, muitas vezes transformados em verdadeiros zumbis, acabam engrossando as cifras da criminalidade. Todos, portanto, somos vítimas do crack.(Zero Hora, 22/09/2013)[grifos nossos]

Já a categoria discursos da violência, por sua vez, foi observada em cinco dos textos. As matérias foram divididas entre as que apresentavam o discurso erudito e o senso comum. Três delas - "Recall de tornozeleiras: 500 presos na rua sem vigilância" (reportagem - 27/08/2013); "O tamanho da tragédia" (editorial - 22/09/2013); "Guerra urbana: na hora e no local errados" (reportagem especial - 22/09/2013) - tinham um caráter mais analítico e, por isso, apresentaram ambos os discursos. Já outros dois textos - "Crime em família: garoto é suspeito de matar pai a tiro" (notícia - 27/08/2013) e "Nem a escola escapa da guerra das quadrilhas" (nota - 11/10/2013), devido à brevidade do formato, apresentaram apenas o discurso senso comum.

Para Damatta (1993), ambos os discursos,erudito e senso comum da violência se fazem presentes na sociedade, na medida em que elesse complementam, e muitas vezes, são até mesmo simétricos.Nas matérias analisadas ambas as formas discursivas apareceram diversas vezes ao longo dos textos. Ao mesmo tempo em que a reportagem especial "Guerra Urbana: na hora e no local errado", faz, por exemplo, um mapeamento da violência nos bairros mais pobres de Porto Alegre, o que é característico do discurso erudito, também reconstrói a trajetória individual de vítimas do tráfico com depoimento de amigos e familiares, o que remete ao do senso comum, conforme o trecho-exemplo:

Ex: A pipoca espocava no microondas, enquanto a cerveja gelava no freezer, a poucos metros da TV ligada, à espera do desfile da escola de samba do bairro. Eram 23h30min de 9 de fevereiro, na Restinga, zona sul da Capital, e a morte rondava a casa de Luciano Trindade da Rosa. (Zero Hora, 22/09/13) [grifos nossos]

Nos cinco textos elencados foram constados a existência de ambas as categorias em três matérias. Já individualização das vítimas, embora tenha aparecido apenas na reportagem especial "Guerra urbana: na hora e no local errados", é bastante expressiva, uma vez que nelasão reconstruídas as histórias individuais de quatro vítimas da violência do tráfíco. Tais

Comun. \& Inf., Goiânia, GO, v. 18, n. 1, p. 07-20, jan./jun. 2015 
narrativas apresentam dados pessoais das vítimas, como nome, profissão e idade, além do local em que foramassassinadase também recontam como foram os últimos momentos de vida de cada uma delas, como pode ser observado em trecho extraído da matéria:

Tudo indicava um sábado de carnaval tranquilo. A água recém havia voltado às torneiras de casa, e o gráfico, de 34 anos, aproveitou para encher a piscina plástica, na parte da frente do prédio. Preparava o terreno para curtir a manhã de sol do dia seguinte com a irmã e com os sobrinhos. Mas Luciano só tinha alguns segundos de vida. Em frente ao portão, um homem armado de revólver tentou matar outro em razão de uma desavença por drogas. E um dos tiros acertos em cheio a testa de Luciano. (Zero Hora, 22/09/13) [grifos nossos]

O traço comum de todos os personagens presentes nessa reportagem é que se tratavam dehomens jovens e trabalhadores, que não possuíam relações diretas com a criminalidade e com a violência. A ideia central que a reportagem permite inferir é que o tráfico tem vitimado, de forma fatal, até mesmo indivíduos que não possuem envolvimento com ele

Através da análise sistemática das categorias discursivas que têm predominância nas notas, notícias e reportagensanalisadas, foi observada a proeminência da que indica o sentido de risco nos conteúdos selecionados. O aparecimento dela é seguido, em ordem de recorrência nos textos, pelas categorias discursos da violência e individualização das vítimas.

É importante ressaltar que as categorias de sentido observadas apenas tiveram aparecimento nos enunciados do jornal Zero Hora. Elas não puderam ser observadas nos textos do Correio do Povo. As matérias analisadas se caracterizaram por um tipo de construção discursiva diferente do da Zero Hora, já que não se propuseram a fazer diagnósticos, mas, em sua maioria, relatos breves sobre apreensões, flagrantes e operações policiais.

\section{CONSIDERAÇÕES FINAIS}

Ao fim desta análise, identificamos que a cobertura sobre o consumo e circulação de drogas na sociedade apareceu principalmente atrelada às notícias sobre apreensões e flagrantes policiais e também prisões por tráfico de drogas. Esse enquadramento teve maior destaque no jornal Zero Hora, do qual extraímos 11 das 19 matérias analisadas. O Correio do Povo foi o único que trouxe, por duas vezes, notas divulgando palestras abertas e gratuitas da área da saúde que visavam discutir o consumo de drogas lícitas e ilícitas para além do viés punitivista.

Comun. \& Inf., Goiânia, GO, v. 18, n. 1, p. 07-20, jan./jun. 2015 
Também observamos, extrapolando os limites do objetivo proposto para esse artigo, que 9 das 19 matérias possuíam apenas uma fonte policial, que definiu os parâmetros em que se daria a discussão do fato relatado. A escolha das fontes e a definição primária dos fatos oferecidas por elas se mostrou bastante relevante na construção dos sentidos nos textos analisados. Para dar ênfase ao discurso sobre o risco e a insegurança foi utilizado, ainda, por diversas vezes, expressões bélicas, como, por exemplo, "exército de dependentes", "guerra silenciosa", "guerra" e "facções", como mostram os trechos das matérias expostos anteriormente. $\mathrm{O}$ uso de tais expressões reforça a ideia de guerra às drogas, lógica fornecida pelas fontes institucionais das polícias e outras forças coercitivas que possuem um discurso institucional que aborda o tráfico como Inimigo do Estado e que são, muitas vezes, as únicas consultadas antes da elaboração do texto.

Por fim, consideramos, a partir não apenas deste recorte, mas de todo o esforço monográfico realizado, que leva em conta também outras variáveis, que a restrição da diversidade de fontes e de outros enquadramentos que não pelo viés punitivista e legalista não somente prejudica o parco debate social sobre drogas, mas fomenta a sensação de insegurança e o medo que os indivíduos têm uns dos"outros", reforça o risco que o "outro" nos representa, numa forma de jornalismo que coloca de lado seu caráter de mediador dos conflitos sociais e toma para si a posição de vigilante das normas, valores e condutas aceitáveis.

\section{REFERÊNCIAS}

DAMATTA, R. Conta de mentiroso:sete ensaios de antropologia brasileira. Rio de Janeiro: Rocco, 1993.

JOVCHELOVITCH, S. Psicologia, saber, comunidade e cultura. Psicologia e Sociedade,Porto Alegre, v.16. n. 2, p. 20-31, 2004.

JOVCHELOVITCH, S. Representações sociais e esfera pública: a construção simbólica dos espaços públicos no Brasil. Petrópolis: Vozes, 2000.

MUSUMECI, L. Estatísticas de segurança: para que servem e como usá-las. In: RAMOS, S., RAMOS, S., PAIVA, A. Mídia e violência: tendências na cobertura de criminalidade e segurança no Brasil. Rio de Janeiro: IUPERJ, 2007.p. 151- 176.

ORLANDI, E. Análise de discurso: princípios e procedimentos. Campinas: Pontes, 2009.

REINER, R. Media made criminality: the representation of crime in the mass media. In: REINER, R.; MAGUIRE, M.; MORGAN, R. (Orgs).The Oxford Handbook of Criminology. Oxford University Press, Oxford, UK, 2012.

RODRIGO, A. M. Aconstrução da notícia. Petrópolis: Ed. Vozes, 2009. 
SILVA, J. A violência da Mídia. In: RAMOS, S., PAIVA, A. Mídia e violência: tendências na cobertura de criminalidade e segurança no Brasil. Rio de Janeiro: IUPERJ, 2007, p. 93-97.

VAZ, P. Risco e Justiça. In: TERESA CRISTINA B. (Org.), Michel Foucault: entre o murmúrio e a palavra. Campos: Faculdade de Direito de Campos, 2004, p. 101-131.

WELCH, M.; FENWICK, M.; ROBERTS, M. State Managers, intellectuals, and the media:a content analysis of ideology in experts' quotes in feature newspaper articles on crime. Justice Quarterly, Estados Unidos, v. 15, p. 219-241, 1998.

Recebido em:30/09/2014

Aceito em:05/12/2014

Publicado em: 15/06/2015 